\title{
AN ANALYSIS AND CHARACTERIZATION OF LIGHT AND
}

\section{HEAVY CRUDE OILS WITH REFERENCE}

\section{TO MALTENES AND ASPHALTENES}

\section{KETHINENI CHANDRIKA ${ }^{1}$, S. SUDHAKAR BABU ${ }^{2}$, MADABATTULA \\ RAJASEKHAR $^{1} \&$ VIVEK DUGGIRALA ${ }^{1}$}

${ }^{1}$ Department of Petroleum Engineering, Koneru Lakshmaiah Education Foundation, Vaddeswaram, Guntur, Andhra Pradesh, India

${ }^{2}$ Associate Professor, Department of Mechanical Engineering, Koneru Lakshmaiah Education Foundation,

Vaddeswaram, Guntur, Andhra Pradesh, India

\begin{abstract}
Physical and chemical characterization of two crude oils of Indian origin has been studied. Physical properties are consistent with other light and heavy crude oils. Chemical composition revealed high maltenic content with light crude when compared to the heavy crude oil. UV, visible spectrophotometric studies on asphaltenes of both light and heavy crude showed higher absorption in both $U V$ region and visible region of the absorption spectra establishing the fact that asphaltenes are the major contributors to the absorbance of the raw crude oils in the visible region. Significant variation was found in the maltenic content of light and heavy crude oils in terms of their aliphatic hydrocarbons. Gas chromatography studies revealed higher carbon chain length of aliphatics in heavy crude compared to light crude oils. FTIR studies revealed confirmation of $\mathrm{C}$-H stretching vibrations, carbon-carbon stretching and aliphatic $C=H$ bending modes, a characteristic of petroleum liquids.
\end{abstract}

KEYWORDS: Asphaltene, Maltene, Crude Oil, Aliphatics \& Heptanes

Received: Dec 01, 2018; Accepted: Dec 21, 2018; Published: Jan 30, 2019; Paper Id.: IJMPERDDEC201895

\section{INTRODUCTION}

Characterization of crude oil fractions is very important for optimization of product performance, refining processes, understanding structural property, and environmental issues ${ }^{[1]}$

Crude oils in the petroleum industry have been classified into Light and Heavy oils based on their densities, flow properties, specific gravity and the American Petroleum Institute gravity (API gravity). Light crude is a liquid petroleum product that has low density and flows freely at room temperature.

Light crude is predominately rich in light hydrocarbon fractions because of which its exhibits low specific gravity, low viscosity, low specific gravity and high API gravity. It generally has a low wax content. On the contrary, heavy crude oil does not flow easily. It has more density or specific gravity higher than that of light crude oil. Heavy crude oils generally have an API gravity less than $20^{\circ}{ }^{[2]}$ while extra heavy oil has an API gravity below $10.0^{\circ} \mathrm{API}$. API gravity generally measures how dense or light a petroleum liquid is compared to water. If its API gravity of specific petroleum liquid is greater than 10, it is lighter and floats on water; if less than 
10 , it is heavier and sinks.

Commercially, light crude oil has a higher market price than heavy crude oil because it produces a higher amount of gasoline and diesel fuel when converted into products by an oil refinery. Heavy crude oil has more negative impact on the environment than its light counterpart since its refinement requires the use of more advanced techniques

Petroleum products generally have saturates ${ }^{[3]}$, aromatics ${ }^{[4]}$, resins ${ }^{[5]}$ and asphaltenes ${ }^{[6]}$. Saturates are mainly aliphatic molecules with few branching structures. Saturates amount to 5-20\% of a heavy oil ${ }^{[7]}$ with a molecular weight ranging between $470-880 \mathrm{~g} \mathrm{~mol}^{-1}$. Aromatics amounts to $15-35 \%$ of a heavy oil and are in the form of a yellow to red coloured liquid.

They are constituted of few condensed aromatic rings substituted with aliphatic chains and have a molecular weight equal to about $570-980 \mathrm{~g} \mathrm{~mol}^{-1[8]}$

Resins amount to $12-45 \%$ of a heavy oil ${ }^{[7]}$. They form a black solid at room temperature. Their composition is close to that of asphaltenes even though they exhibit a lower molecular weight, varying from 780 to $1400 \mathrm{~g} \mathrm{~mol}^{-1}$, a somewhat higher H/C ratio between 1.38 and 1.69 and a less complex aromatic structure with $2-4$ fused rings ${ }^{[8]}$

Maltenes constitute the heptane soluble fraction of crude oil. Waxes, saturates, aromatics constitute the major part of maltenes ${ }^{[9]}$. Asphaltenes amount to $5-20 \%$ of a heavy oil, in a few cases, they reach values up to $43 \%$ [7]. Asphaltenes form a black powder at room temperature when eluted by n-heptane and they are largely responsible for the black colour of the crudes. Asphaltene is also the heaviest and most polar molecule in crude oil ${ }^{[10]}$

Asphaltenes are operationally defined as the crude oil components which is soluble in toluene and insoluble in n-heptane. It is often more convenient to perform pentane or heptane extraction for separating the three fractions (saturates, aromatics, resins) soluble in pentane/heptane as maltenes, from the other pentane/heptane insoluble fraction (asphaltenes).

In a study ${ }^{[11]}$ the physical and chemical characteristics of Nigerian crude oils were established. In this work among the oils tested, the average specific gravity was 0.871 and the API gravity was around 31 . However, the pour point varied, ranging from $+25-+35$. The gas chromatography results showed both aromatic and nonaromatic fractions. Aromatic predominately comprise n-hexanes, n-heptane, cyclohexane, n-octadecane, n-nonane, n-dodecane, similarly aromatic fractions comprised benzene, toluene, o-xylene, p-xylene.

Previous work ${ }^{[12]}$ reported average maltenic content of $77 \%$ and asphaltenic content of $22 \%$.

FTIR, Gas Chromatography and UV visible studies revealed aliphatics distribution in maltenic fraction. Light hydrocarbons ranging from C13-C15 were observed in their study.

In this study, we reported physical, chemical characterization of light crude oil and heavy crude of south \& north Indian origin. A comprehensive study on their malteneic and asphaltenic fractions has been undertaken using UV- visible spectroscopy, Gas Chromatography \& FTIR spectroscopy. A comparison was made and attributions were made for the existing differences between these fractions. 


\section{MATERIAL AND METHODS}

Two crude oils; Light crude (ONGC-Rajahmundry, South India) and Heavy crude (Gujarat, North India) denoted by Sample A (Light crude oil) and Sample B (Heavy crude oil) respectively, were used in this study. The chemical-physical analyses were run on the raw crude oils and their maltenic and asphaltenic fractions. Heptane and toluene (ACS grade, Sigma Aldrich) were used for the raw crude oil fractionation. Dichloromethane: DCM (ACS grade, Sigma Aldrich), was used as solvent for most of the spectroscopic analyses. Physical properties of both oils are listed in Table 1

Table 1: Physical Properties of Crude Oils

\begin{tabular}{|c|c|c|c|c|}
\hline Properties & Units & Method & Sample A & Sample B \\
\hline Specific gravity & None & Hydrometer & 0.935 & 0.952 \\
\hline API gravity & ${ }^{\circ}$ API & ASTMD 28 & 19.28 & 16.97 \\
\hline Pour point & ${ }^{\circ} \mathrm{C}$ & IP15/55 & 8 & 31 \\
\hline viscosity & CP & P226/91 & 1.98 & 3.01 \\
\hline
\end{tabular}

\subsection{Experimental Procedure for Sample Preparation}

The crude oil fractions are broadly categorized into heptane soluble and toluene soluble fractions. The Heptane soluble fraction is regarded as maltene and the heptane insoluble as asphaltene. The Asphaltenes are subsequently solubilized in toluene for chemical analysis. Both Sample A \& B and their corresponding maltenic and asphaltenic fractions are kept for chemical characterization using Fourier transformation infrared spectroscopy (FTIR), Gas Chromatography (GC) and UV-Vis Spectroscopy.

\subsection{Preparation of Maltenes and Asphaltenes}

\subsubsection{Asphaltene Separation}

Two grams of oil were used for the precipitation of the asphaltenes. Asphaltene fractions were precipitated from the oils using reagent grade $n$-heptane at a $60: 1 \mathrm{v} / \mathrm{w}$ (solvent to oil ratio) at room temperature. The n-pentane was gently agitated and the oils were added drop wise over a period of $20 \mathrm{~min}$. The samples were left to sit for $1 \mathrm{~h}$ at room temperature followed by centrifuging at 3000 RPM for 5 min using a Thermo Fisher Sorval ST 16 R centrifuge. Asphaltene solids that adhered to the side of the centrifuge tubes were separated from $n-$ pentane and oven dried at $105^{\circ} \mathrm{C}$. The mass percent of asphaltenes as heptane insoluble (HI) is calculated as the percentage by weight of the original sample as follows:

$$
\mathrm{HI}, \%=\mathrm{A} / \mathrm{B} \times 100
$$

Where:

$$
\begin{aligned}
& A=\text { total mass of insoluble }, \text { and } \\
& B=\text { total mass of the sample. }
\end{aligned}
$$

\subsubsection{Maltene Separation}

For heavy crude oil, $10 \mathrm{~g}$ of the sample is weighed into a 2-L Erlenmeyer flask and around $300 \mathrm{ml}$ of n-heptane were added. Through stirring, a good dispersion of the oil was assured. The flask was then heated to $90^{\circ} \mathrm{C}$ and kept at that temperature for around 1.5 hours. Afterwards, the bottle was set aside and left for cooling and sedimentation of particles overnight. The next day, the dispersion was filtered through a Buchner-funnel and the filter paper was folded and inserted 
into a soxhlet extractor filled with around $700 \mathrm{ml}$ of $\mathrm{n}$-heptane. The extraction was kept running for 72 hours. Subsequently, the liquid phase was combined with the filtrate and used for analysis. In case of light crude oil a 50\% dilution with n-heptane was used and the solution was filtered through a Buchner-funnel. The filtrate is directly used for analysis

\subsubsection{FT-IR Analysis}

Fourier transform - Infrared Spectroscopy, Spectrum Two ${ }^{\mathrm{TM}}$ was purchased from Perkin Elmer (USA). LiTa03 (Lithium tantalite) pyroelectric infrared detector was used to scan the samples. Sample A and B, their maltenic fractions are dissolved in heptane and were directly applied to the Potassium bromide (KBr) glass windows with $4 \mu$ path length. All the spectra were smoothed and analysed by using Spectrum 10 version 10.3.06 software.

\subsubsection{UV-Visible Spectroscopy}

UV-Vis spectra (230-1000 nm wavelength region) of the raw crude oils and solvent-separated fractions, dissolved in DCM $\left(0.01 \mathrm{mg} \mathrm{mL}^{-1}\right.$ concentration), were measured by using $1 \mathrm{~cm}$ quartz cuvettes on an HP 8453 diode array spectrophotometer ${ }^{[13,14]}$

\subsubsection{Gas Chromatography}

The qualitative composition of the raw crude oils and their corresponding maltenic fractions was determined by a Thermo GC, 8610. India, equipped with a $-\mathrm{OV}-1$ capillary column $(60 \mathrm{~m} \times 0.25 \mathrm{~mm}$ i. d., $0.25 \mathrm{~mm}$ film thickness $)$. Nitrogen was used as carrier gas with a constant flow rate of $1.0 \mathrm{ml} \mathrm{min}^{-1}$. The oven temperature started from $50^{\circ} \mathrm{C}$, held for $0 \mathrm{~min}$, and increased up to $350^{\circ} \mathrm{C}$ with a heating rate of $10^{\circ} \mathrm{C} \mathrm{min}^{-1}$. All the peaks are identified with standard (Sigma Aldrich) hydrocarbon cocktail mixtures ranging from C8-C20 and C20-C40

\subsection{Physical Characterization of Light and Heavy Crude Oils}

Table 1 shows four physical properties viz., specific gravity, API gravity, pour point and viscosity. Oils with higher specific gravity implicate the greater resistance to flow and hence relatively the light crude (Sample A) is at lower scale when compared to heavy crude (Sample B). Likewise, heavy crude oils usually exhibit API gravity below $20^{\circ}$. The lower the API gravity the heavier is the fluid. API comparison shows Sample B $\left(16^{\circ}\right)$ is heavier than Sample -A $\left(19.83^{\circ}\right)$. Previous work ${ }^{[15]}$ shows 11 crude oil samples whose API gravity were in between $19^{\circ}-41^{\circ}$. Pour point (PP) are high for heavy crudes as it measures the temperature at which oil assume semisolid nature. High pour points are generally associated with high paraffin content. The results again indicate higher scale of pour point for sample B (PP: 31 ) as against sample A (PP; 8). Viscosity is higher for Sample B than Sample A. Thus, Low specific gravity, higher the API gravity, low pour point and low viscosity are the characteristic features of light oils which were confirmed with the present results.

\subsection{Compositional Analysis of Crude Oils}

The results obtained through solvent extraction and proximate analysis are shown in Table 2 . Maltenes and asphaltenes are approximately the $62.75 \%$ and 37.25 wt. \% of the heavy raw crude oil, respectively. Light crude oil, however, did not show much of the asphaltene content. Only $2 \%$ asphaltene is derived from light crude. This shows the larger viscosity contribution in heavy crude is contributed by asphaltenes. Work by Buckley et al. $1998^{[15]}$ also confirms a low asphaltene weight fraction ranging in between 3.8-10.9\%. The proximate analysis shows small differences between the two samples in terms of fixed carbon however, some differences could be observed with respect to 
humidity and ash content.

Table 2: Compositional Analysis of Raw Crude Oils. Maltenes and Asphaltenes are Determined by n-Heptane and Toluene Solubilization of Heptane Insoluble

\begin{tabular}{|c|c|c|}
\hline Parameter & Sample A & Sample B \\
\hline Maltenic content & 98.0 & 65.0 \\
\hline Asphaltenic content & 2.0 & 35.0 \\
\hline Volatiles (wt\%) & 85.6 & 85.3 \\
\hline Ash (wt\%) & 0.06 & 0.32 \\
\hline Humidity (wt\%) & 0.12 & 0.08 \\
\hline
\end{tabular}

\subsection{UV -Visible Spectroscopy}

UV, visible studies were undertaken to establish the absorption behaviour of maltene and asphaltene absorption coefficients of light oil and heavy oil constituents. The UV-Vis absorption spectra (Figure1a,1b,1c and Figure1a', Figure1b' and Figure 1c') of the two crude oils and their heptane and toluene fractions were kept for analysis. Maltenes and asphaltenes showed decrease in absorption coefficients from the UV region to Visible region, which is a unique to aromatic compounds ${ }^{[13]}$. As seen from the spectra there is no major difference between the two samples, either for raw crude oils or for their maltenic and asphaltenic fractions. UV-Vis spectra of the raw crude oils are similar to those of the maltenic fractions, manifested by significant absorption in the UV region and lower absorption in the visible region above $450 \mathrm{~nm}$.

Crude oils and their maltene fractions have lower absorption in the visible region. On the contrary, asphaltenes showed higher absorption in both UV region and visible region of the absorption spectra establishing the fact that asphaltenes are the major contributors to the absorbance of the raw crude oils in the visible region. The characteristic peak, typical of porphyrins, can be manifested at about $420 \mathrm{~nm}$, unique only to asphaltenes in the UV-Vis spectra confirming that this feature is exhibited by asphaltenes and not by other components of the oils ${ }^{[16]}$. The absorbance of each sample are shown in Figure1a, 1b, 1c and Figure1a', Figure1b'as a function of the wavelength to depict and portray the absorption properties of the raw crude oils and solvent fractions in the entire UV-this range.
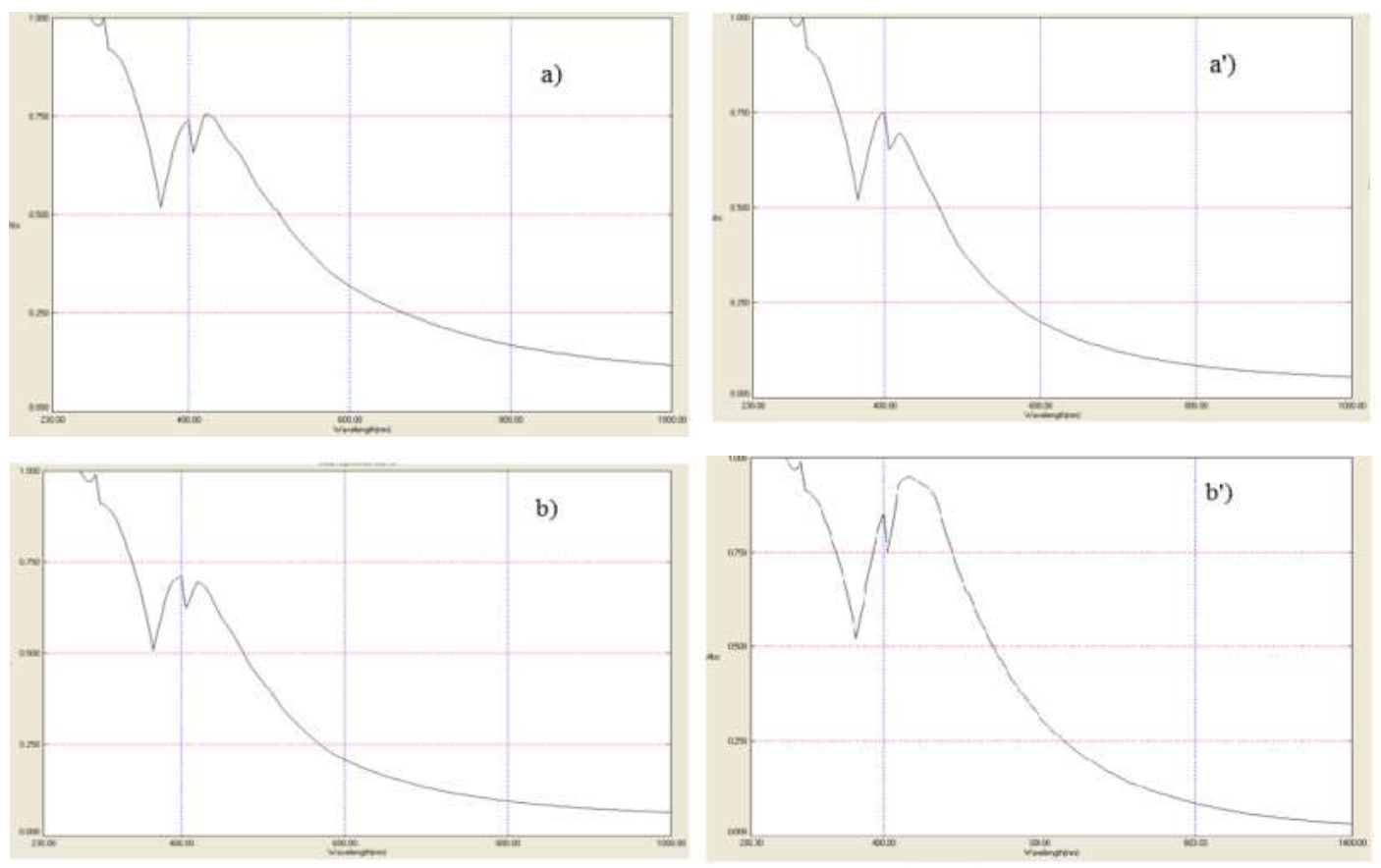

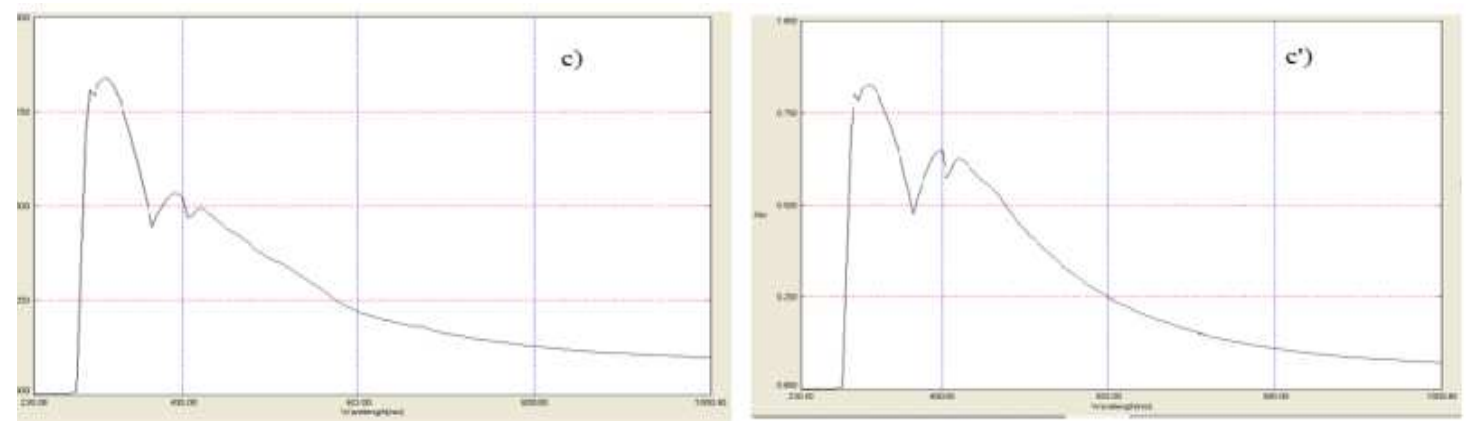

Figure 1: a) UV-Vis. Spectrum of Light Crude Oil; b) Light Crude Oil Maltene Fraction; c) Light Crude Oil Asphaltene Fractions; a') Heavy Crude Oil; b') Maltene Fraction of Heavy Crude c') Asphaltene Fraction of Heavy Crude

\subsection{GC Analysis}

The GC chromatograms of the two raw crude oils and of their maltenic fractions, shown in Figure 2a, $2 \mathrm{~b}$ and Figure 2a', 2b' for light and heavy crude oils respectively. The large spectrum of peaks was detected in between 2 and 7 min for light crude oil and its maltenic fraction, Heavy crude oil however showed abundant aliphatic carbons from 10min and $17 \mathrm{~min}$. No difference was found between the crudes and their maltenic fractions. However, comparison among the maltenic fractions of crudes (sample A\&B) showed well isolated and intensified aliphatic peaks with heavy crude oil.
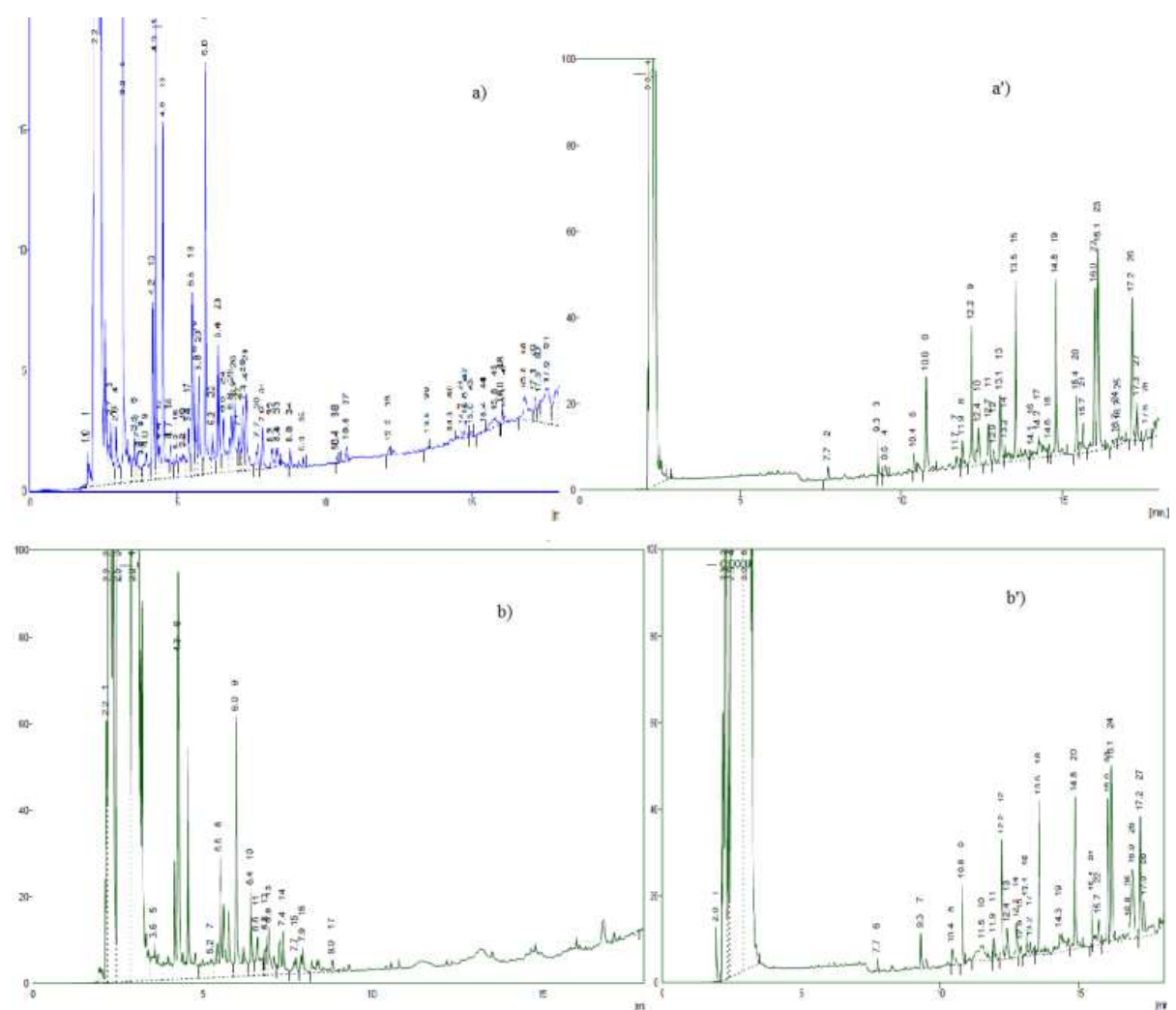

Figure 2: a GC. Chromatogram of Light Crude Oil; b Light Crude Oil Maltene Fraction; c Light Crude Oil Asphaltene Fractions; a') Heavy Crude Oil; b') Maltene Fraction of Heavy Crude c') Asphaltene Fraction of Heavy Crude

Relatively shorter carbon chains (C8- C20) were found with light crude oil than heavy crude whose chain length varied in between $\mathrm{C} 20-\mathrm{C} 40$. Earlier works ${ }^{[12]}$ revealed the presence of $\mathrm{C} 13-\mathrm{C} 15$ in the maltenic fraction of light crude oil 
sample. In this work, maltenic fractions of light crude and heavy crude showed elution of significant aliphatic hydrocarbons with boiling points ranging from $91-123^{\circ} \mathrm{C}$ and $108-171^{\circ} \mathrm{C}$ respectively. Maltenic compounds are highly solubilized in heptane and hence aliphatics are presumed to be the key compounds eluted and detected by gas chromatography

\subsection{FTIR Spectroscopy Studies}

The peaks in an IR spectrum correspond to the vibrational frequencies of the chemical bonds in the sample. No two infra-red spectra are the similar since each compound has a unique arrangement of atoms in the sample. Thus, IR provides an identification of the chemical groups in a sample

In this work, asphaltenes are characterized by FTIR analysis, which was otherwise not possible to characterize by gas chromatography analysis. The FTIR spectrum of any petroleum liquid can be broadly characterized by three absorption regions: i) a region between 3100 and

$2900 \mathrm{~cm}^{-1}$ due to $\mathrm{C}-\mathrm{H}$ stretching vibrations; ii) a region between 1600 and $1000 \mathrm{~cm}^{-1}$ due to carbon-carbon stretching and aliphatic $\mathrm{C}=\mathrm{H}$ bending modes; iii) a region between 1000 and $600 \mathrm{~cm}^{-1}$ featured by the characteristic bands of the aromatic $\mathrm{C}=\mathrm{H}$ out-of-plane bending modes ${ }^{[17,18]}$

The FTIR spectra of the crude oils and their maltenic and asphaltene fractions were compared in Figure $3 \mathrm{a}, 3 \mathrm{~b}$ and Figure 3a', 3b'. Two samples of heavy, light crude, their maltenic and asphaltene fractions exhibited similar trends in absorption regions. A major characteristic peak at $2914 \mathrm{~cm}^{-1}$ corresponds to $\mathrm{CH}_{2}$ asymmetric stretch. Peak at $1460 \mathrm{~cm}^{-1}$ corresponds to both methyl and methylene groups having $\mathrm{C}-\mathrm{H}$ bending vibrations.

Methyl groups exhibit an umbrella mode $\mathrm{C}-\mathrm{H}$ bend at $1375 \pm 10 \mathrm{~cm}^{-1}$. This peak is clearly seen in Figure $3 \mathrm{a}$, $3 \mathrm{~b}$ and $3 \mathrm{c}$ at $1379 \mathrm{~cm}^{-1}$ and, along with the two $\mathrm{CH}_{3}$ stretching peaks, confirms the presence of methyl groups in this sample. Methylene groups have a $\mathrm{CH}_{2}$ rocking vibration that falls at $720 \pm 10 \mathrm{~cm}^{-1}$ but only if there are alkyl chains present with four or more $\mathrm{CH}_{2}$ groups in a row. Since the spectrum clearly has a peak at $722 \mathrm{~cm}^{-1}$ this means there are alkyl chains present with at least four methylenes in a row. Other minor peaks at 1147 and 982 aromatic $\mathrm{C}=\mathrm{H}$ in-plane bending and stretching respectively. Heavy crude has relatively higher asphaltene content than the maltene content. Heavy crude also bound to exhibit the typical characteristic brands as seen in light crude oils. Predominant peaks (Figure 3a', 3b', 3c') at $3036 \mathrm{~cm}^{-1}, 2945 \mathrm{~cm}$
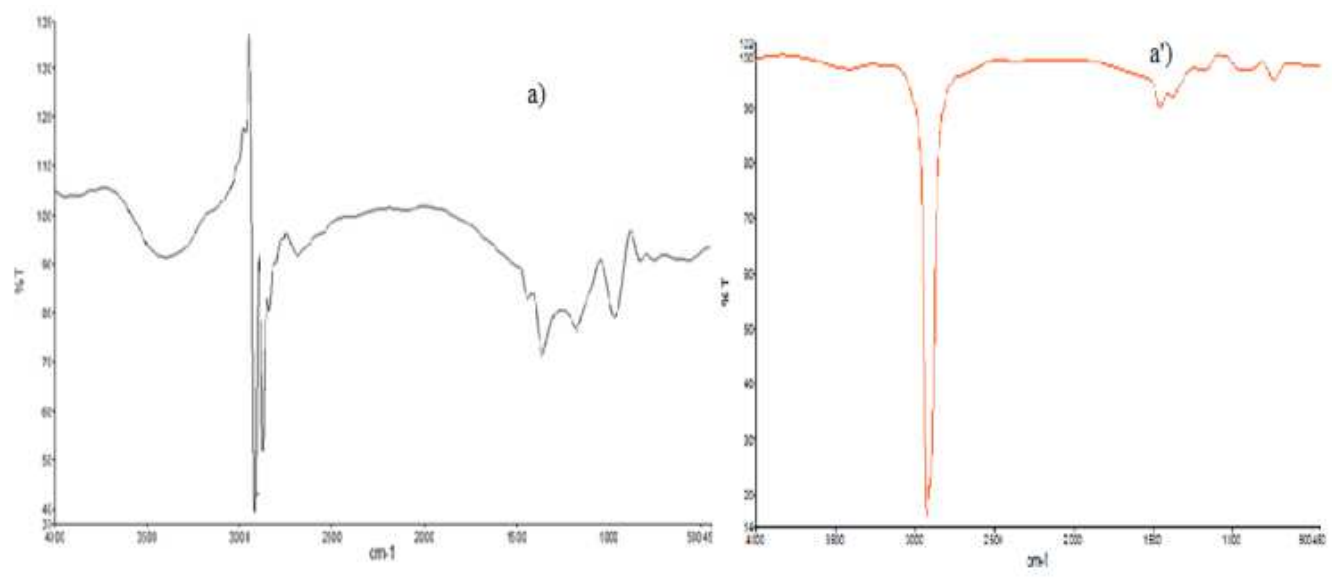

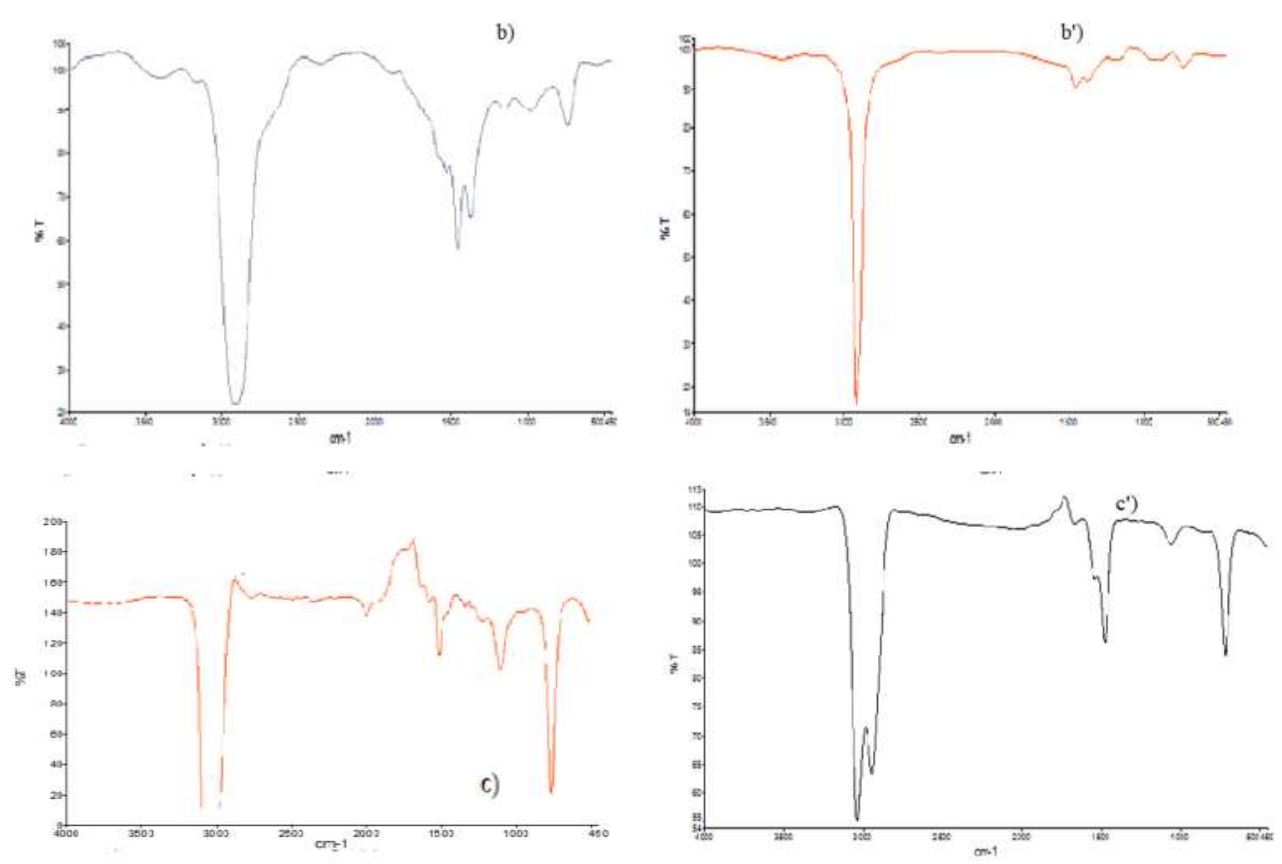

Figure 3: a) FTIR Spectroscopy of Light Crude Oil; b) Light Crude Oil Maltene Fraction;

c) Light Crude Oil Asphaltene Fractions ; a') Heavy Crude Oil; b') Maltene Fraction of Heavy Crude c') Asphaltene Fraction of Heavy Crude

\section{CONCLUSIONS}

Characterization of the raw crude oils and their fractions (maltenes and asphaltenes) was carried out with spectrophotometric and chromatographic techniques. Physical properties of both oils are consistent with other reported light oils and heavy crude oils. Compositional analysis showed higher maltenic content with light crude when compared to heavy crude oil. UV- visible spectrum shows UV-Vis absorption spectra of the raw crude oils are very similar to those of the maltenic fractions, Spectrophotometric studies of asphaltenes (both light and heavy crude) showed higher absorption in both UV and visible region of the absorption spectra proving the fact that asphaltenes contribute to the absorbance of the raw crude oils in the visible region. Gas chromatography studies revealed a higher range of carbon chain length in heavy crude compared to light crude oil. FTIR studies revealed confirmation of long chain aliphatics typical of petroleum fuels.

\section{ACKNOWLEDGEMENTS}

The authors thank the management of KLEF (Deemed to be University) for supporting and encouraging this work by providing the facilities in Department of Petroleum Engineering and Bioprocess Technology Research Center.

\section{REFERENCES}

1. Park, S.; Ali Mansoori, G.: Aggregation and Deposition of Heavy Organics in Petroleum Crudes. Energy Sources. 1988, 10, $109-125$

2. Martínez-Palou, R.: Mosqueira, M.: Zapata-Rendón, B.: Mar-Juárez, E.: Bernal-Huicochea, C.: de la Cruz Clavel-López, J.: et al. Transportation of heavy and extra-heavy crude oil by pipeline: A review. Journal of Petroleum Science and Engineering. 2011, 75, 274-282

3. Aske N, Kallevik H, Sjöblom, J. Determination of Saturate, Aromatic, Resin, and Asphaltenic (SARA) Components in Crude Oils by Means of Infrared and Near-Infrared Spectroscopy. Energy \& Fuels. 2001, 15, 1304-1312 
4. Jinggui, L.: Philp P.: Zifang M.: Wenhui, L.: Jianjing, Z.: Guojun, C. et al. Aromatic compounds in crude oils and source rocks and their application to oil-source rock correlations in the Tarim basin, NW China. Journal of Asian Earth Sciences. $2005,25,251-268$

5. Demirbas, A.: Taylan O. Removing of resins from crude oils. Petroleum Science and Technology. 2016, 34, 771-777

6. Davangeri, M. B., Vinay, B. U., \& Bhat, V. (2014). Development And Evaluation Of Mechanical Properties Of Asbestos Filled E-Glass/Epoxy Composites. Development, 4(1), 25-30.

7. Thanh, N.: Hsieh, M.: Philp R. Waxes and asphaltenes in crude oils. Organic Geochemistry. 1999, 30, 119-132

8. Hinkle, A.: Shin, E.: Liberatore, M.: Herring, A.: Batzle, M. correlating the chemical and physical properties of a set of heavy oils from around the world. Fuel. 2008, 87, 3065-3070

9. Lesueur, D. The colloidal structure of bitumen: Consequences on the rheology and on the mechanisms of bitumen modification. Advances in Colloid and Interface Science. 2009, 145, 42-82

10. Alcazar-Vara, L.: Buenrostro-Gonzalez, E. Characterization of the wax precipitation in Mexican crude oils. Fuel Processing Technology. 2011, 92, 2366-2374

11. Aske, N.: Kallevik, H.: Johnsen, E.: Sjöblom, J. Asphaltene Aggregation from Crude Oils and Model Systems Studied by HighPressure NIR Spectroscopy. Energy \& Fuels. 2002, 16, 1287-1295

12. Palanisamy, K. L., Devabharathi, V., \& Sundaram, N. M. (2013). The utility of magnetic iron oxide nanoparticles stabilized by carrier oils in removal of heavy metals from waste water. International Journal of Research in Applied, Natural and Social Sciences, 1(4), 15-22.

13. Odebunmi, E.: Ogunsakin, E.: Ilkhor, P. Characterization of crude oils and petroleum products: (I) Elution liquid chromatographic separation and gas chromatographic analysis of crude oils and petroleum products. Bulletin of the Chemical Society of Ethiopia. 2002, 16,115-132

14. Merola, M.: Carotenuto, C.: Gargiulo, V.: Stanzione, F.: Ciajolo, A.: Minale, M. Chemical-physical analysis of rheologically different samples of a heavy crude oil. Fuel Processing Technology. 2016, 148, 236-247

15. Wang, J.: Li, C.: Zhang, L.: Que, G.: Li, Z. The Properties of Asphaltenes and Their Interaction with Amphiphiles. Energy \& Fuels. 2009, 23, 3625-3631

16. Campardelli, R.: Della Porta, G.: Gomez, L.: Irusta, S.: Reverchon, E.: Santamaria, J. Au-PLA nanocomposites for photothermally controlled drug delivery. J Mater Chem B. 2014, 2, 409-417

17. Buckley, J.: Hirasaki, G.: Liu, Y.: Von drasek, S.: Wang, J.: Gill, B. Asphaltene Precipitation and Solvent Properties of Crude oils, Petroleum Science and Technology. 1998, 16, 251-285

18. Groenzin, H.: Mullins, O. Molecular Size and Structure of Asphaltenes from Various Sources. Energy \& Fuels. 2000, 14, 677684

19. Mahto, V., \& Singh, H. (2013). Effect of Temperature and Pour Point Depressant on the Rheology of Indian Waxy Crude Oil. International Journal of General Engineering and Technology.

20. Catauro, M.: Bollino, F.: Veronesi, P.: Lamanna, G. Influence of PCL on mechanical properties and bioactivity of ZrO2based hybrid coatings synthesized by sol-gel dip coating technique. Materials Science and Engineering: 2014, 39, $344-351$

21. Silverstein, R.: Webster, F.: Kiemle, D.: Bryce, D. Spectrometric Identification of Organic Compounds, 8th Edition. 2014, NY: Wiley, 
